\title{
Inflammation-mediated changes in haemostatic variables of pulmonary tuberculosis infected subjects in the course of treatment.
}

CHIZOBA 0. OKEKE ( $\sim$ oc.okeke@unizik.edu.ng)

Unizik: Nnamdi Azikiwe University https://orcid.org/0000-0003-0269-095X

GRACE I. Amilo

Unizik: Nnamdi Azikiwe University

PATRICK O Manafa

Unizik: Nnamdi Azikiwe University

NANCY C. Ibeh

Unizik: Nnamdi Azikiwe University

\section{Research Article}

Keywords: Tuberculosis, Haemostasis, Cytokines, inflammation

Posted Date: February 21st, 2022

DOI: https://doi.org/10.21203/rs.3.rs-1344187/v1

License: (c) (i) This work is licensed under a Creative Commons Attribution 4.0 International License.

Read Full License 


\section{Abstract \\ Background}

Tuberculosis (TB) is a chronic infectious disease usually marked by a high level of inflammatory response. Haemostasis and inflammation are closely linked both in health and disease in such a way that inflammation leads to activation of the haemostatic system that in turn influences inflammatory activity. This prospective follow-up study was designed to assess inflammation-mediated changes in haemostatic variables of pulmonary tuberculosis infected subjects in the course of therapy.

\section{Method}

A total of 60 TB-infected individuals, aged 18-65 years participated in the study. The individuals were recruited before commencement of therapy and followed up to 6 month into therapy. Tuberculosis was diagnosed using ZiehI Neelsen acid-fast bacilli test and GeneXpert MTB/RIF assay. Pro-inflammatory cytokines: tumor necrosis factor-alpha (TNF-a), interleukin-6 (IL-6), interleukin-2 (IL-2), anti-inflammatory cytokines: interleukin-10 (IL-10), transforming growth factor-beta (TGF- $\beta$ ) and haemostatic variables: thrombopoietin (TPO) P-selectin (P-SEL), platelet activating factor (PAF), platelet factor-4 (PF-4) and GP $\mathrm{Ilb} / \mathrm{Illa}$ complex were measured by ELISA methods. These parameters were measured at pre-treatment, 2 month and 6 month into therapy. Data were analyzed using SPSS version 22.

\section{Results}

The results showed that TNF-a, IL-6, IL-2 (pro-inflammatory cytokines) and P-selectin, GP IIb/IIla, thrombopoietin (haemostatic variables) were significantly increased at 2 month into therapy compared to pre-treatment values $(p=<0.001,<0.001,<0.001,0.015,0.035$ and 0.017 respectively) and decreased at 6 month into therapy. Also at 6 month into therapy in comparison to 2-month into therapy, there were significant increase in IL-10 and TGF- $\beta$ (anti-inflammatory cytokines) ( $p=0.020$ and 0.001 respectively) as well as a significant decline in PF-4 ( $p=0.030)$. There were significant positive correlations between GP $\mathrm{Ilb} / \mathrm{Illa}$ and TNF-a $(r=0.372 ; p=0.031), \mathrm{LL}-6$ and PSEL $(r=0.413 ; p=0.027), \mathrm{IL}-6$ and TPO $(r=0.335 ; p=0.046)$, PF4 and TGF- $\beta(r=0.463 ; P=0.006)$, while PAF correlated negatively with TGF- $\beta(r=-0.368 ; p=0.032)$.

\section{Conclusion}

The changes in the pro- inflammatory cytokines (TNF-a, IL-6, IL-2) aligned with changes in the levels of Pselectin, GP Ilb/Illa, and TPO in the course of TB therapy. This suggests that inflammation modulates the levels of these haemostatic variables in TB individuals.

\section{Introduction}


Tuberculosis (TB) is caused by Mycobacterium tuberculosis (Mtb), a bacterium that in majority of cases affect the lungs[1]. It is ranked as second only to Human immunodeficiency virus (HIV) infection as the greatest killer worldwide due to a single infectious agent. About one third of the world's population is thought to have been infected with M. tuberculosis. In Nigeria, Tuberculosis is a major public health problem. According to CDC [2], Nigeria is the country worst affected by tuberculosis in Africa and ranks third in the world [2]. Tuberculosis burden in Nigeria is thought to be further compounded by the high prevalence of HIV/AIDS among the general population.

Inflammation is part of the complex biological response of body tissues to harmful stimuli, such as pathogens, damaged cells, or irritants [3], and is a protective response involving immune cells, blood vessels, and molecular mediators. Inflammation plays a dual role in immune response to mycobacterium infection. On the one part, it is a prerequisite for successful pathogen elimination while on the other part, it mediates tissue injury and disease progression. At the onset of the infection, inflammatory reactions are largely protective; during active disease, the deleterious effect of inflammation prevails, making inflammation a paramount pathogenic factor of TB progression. Inflammation in TB infection involves both immune cells such as Neutrophils, lymphocytes and monocytes/macrophages and cytokines such as IL-6, TNF- $a$, IL-10, TGF- $\beta$, IL-1 $\beta$ and IFN-Y [4]. Hence the measurement of inflammatory response in TB subjects involves the assessment of these cells and cytokines.

In TB patients, severe infection and inflammation are known to lead to haemostatic abnormalities, ranging from insignificant laboratory changes to severe disseminated intravascular coagulation (DIC) [5]. Haemostasis is a balanced process that halts bleeding after blood vessels have been traumatized and involves the entire process that maintains the flowing blood in a fluid state and confined to the circulatory system [6]. Thus while inflammation aims at restoring the integrity of damaged or threatened tissues, most frequently because of injury or infectious pathogens, haemostasis is a physiological defence mechanism to stop bleeding due to vessel wall damage [7].

Quite obviously, haemostasis and inflammation are closely linked, both in health and disease. They are tightly interrelated patho-physiologic processes that considerably affect each other. It is a bidirectional relationship in which inflammation leads to activation of the haemostatic system that in turn influences inflammatory activity [8]. It is well established that local activation of the haemostatic system is an essential part of the host defenses in both infectious and non-infectious inflammatory states. This implies that the haemostatic system acts in concert with the inflammatory cascade creating an inflammation-haemostasis cycle in which each activated process promotes the other and the two systems function in a positive feedback loop [9]. Thus the failure of the complex balance between proand anti-coagulation, or between pro- and anti-inflammatory reactions because of genetic or acquired disturbances may result in disease. The many established links between inflammation and coagulation help explain the pro-thrombotic tendency observed in patients with acute inflammatory or infectious diseases [8]. The vast crosstalk between inflammatory and haemostatic systems, involves all components of haemostasis such as the endothelium, platelets, clotting and anticoagulant pathways as well as the fibrinolytic system [10]. Platelets which are blood cells mediate primary haemostasis leading 
to formation of a platelet plug, while the coagulation factors drive the secondary haemostasis leading to formation of a stable fibrin clot [6]. The action of platelet in haemostasis involves adhesion, activation and change of shape from discoid to spiky sphere, release of granular content most of which have haemostatic effect and marks the haemostatic process and platelet aggregation. Each of this action is mediated and marked by a number of measurable parameters such as Platelet factor -4, P-selectin, GP $\mathrm{Ilb} / \mathrm{Illa}$, and Thrombopoietin that regulates the formation of platelets in the bone marrow. It could be assumed that the general effect of inflammation on haemostasis which is already established due to the cross-talk between them would most likely affect these parameters that mediates and marks the activity of platelet in primary haemostasis. This assumption was put to test by this study as the changes that take place in these parameters with inflammation were monitored in TB infected subjects. From the foregoing, it could be deduced that exploring the already established knowledge of a cross-talk between haemostasis and inflammation will strengthen our understanding of the patho-physiological relationship between inflammation and alterations in haemostatic variables in TB infected individuals. This study therefore monitored the changes in the levels of inflammatory cytokines and correlated it with the alterations in haemostatic variables of individuals infected with Tuberculosis in the course of therapy.

\section{Materials And Methods}

\section{Study setting}

This study was conducted at the TB Clinic of Mile Four Hospital Abakaliki Ebonyi State. This is a well known Catholic mission hospital that is a Special Tuberculosis and Leprosy Referral Centre in the region. It is located in Abakaliki, the capital of Ebonyi State, South-Eastern Nigeria and serves patients referred from nearby states.

\section{Study Design}

This study was a longitudinal cohort study in which blood samples were collected from study subjects before commencement of anti-tuberculosis therapy, 2-months into therapy and at 6-months into therapy.

\section{Study Population}

The study population comprised subjects confirmed to be positive for pulmonary tuberculosis by Sputum-Smear Acid Fast Bacilli by Ziehl Neelsen's stain and GeneXpert MTB/RIF assay. The baseline samples were collected before commencement of therapy (pre-treatment) and participants followed up in the course of treatment and samples collected after 2 months and 6 months therapy. Tuberculosis treatment regimen involves two months of therapy (Intensive phase) in which the patients are given 4 fixed dose combination (Rifampicin, Isoniazid, Pyrazinamide and Ethambutol hydrochloride) and the Continuation phase in which the subjects are given Rifampicin and Isoniazid only for 4 months. The dosage of therapy is dependent on the body weight of the subjects.

\section{Sample Size Determination}


Sample size was calculated using G*Power software version 3.0.10 (Universitat Dusseldorf Germany). Power analysis for a repeated measures ANOVA with three measurements was conducted in G*Power to determine a sufficient sample size using an alpha of 0.05 , a power of 0.90 and a medium effect size. Based on these, the calculated sample size was 58.

\section{Tuberculosis subjects}

A total of sixty (60) Tuberculosis subjects aged 18 to 65 years ( $37.53 \pm 15.65$ years) were enlisted for this study. They consist of 35 males ( $38.23 \pm 16.17$ years) and 25 females ( $35.76 \pm 14.59$ years).

\section{Inclusion and exclusion criteria}

Individuals of both gender confirmed to be positive for active pulmonary Mycobacterium tuberculosis were included while individuals with any known bleeding disorders or history of bleeding, pregnant women, those that withheld their consent before or in the course of the study, subjects on aspirin and anticoagulant therapy, females on oral contraceptives, smokers, those taking any local herbal concoctions, individuals that have other known clinical diseases such as cancer, HIV, diabetes, chronic infections, chronic kidney and liver diseases were excluded from the study.

\section{Ethical Consideration}

Ethical approval was obtained from the Ethics committee of Federal Teaching Hospital Abakaliki (FETHA) Ebonyi State with reference number: FETHA/REC/VOL.2/2018/105 and permission was sought and obtained from the management of Mile four hospital Abakaliki before sample collection.

\section{Informed Consent}

The aim of the research was explained to prospective participants and those who gave oral informed consent were recruited into the study. Confidentiality was ensured according to Helsinki declaration.

\section{Research Questionnaire}

Socio-demographic information such as gender, age, marital and educational status, occupation etc. and clinical information such as symptoms, history of infection, blood transfusion, smoking, alcohol use etc were obtained using a standardized questionnaire.

\section{Sample Collection}

\section{Sputum for TB diagnosis}

Sputum samples consisting of one spot sample and one early morning sample was collected in a wide mouth container from the subjects for Acid fast bacilli (AFB) test as well as for the automated GeneXpert MTB/RIF real-time nucleic acid amplification test for rapid and simultaneous detection of TB and Rifampicin resistance. 


\section{Blood sample collection}

All the necessary precautions were observed in collecting and processing the blood samples. Eight millilitres $(8 \mathrm{ml})$ of blood sample was collected from each subject before commencement of therapy and at 2-months and 6-months into therapy. Three millilitres $(3 \mathrm{mls})$ was dispensed into plain sample bottles. Serum was obtained after clotting by spinning at 3000rpm for 10 minutes and used for evaluation of Tumor Necrosis Factor - alpha (TNF-a), IL-10, IL-6, IL-2, Transforming growth factor-beta (TGF- $\beta$ ), Thrombopoietin and HIV screening. Also, two and half millilitres $(2.5 \mathrm{ml})$ of blood were dispensed into $0.28 \mathrm{ml}(280 \mu \mathrm{l})$ of $3.2 \%$ tri-sodium citrate to give a final blood: tri-sodium citrate ratio of $9: 1$. The sample was mixed properly by reverse uniform inversion and centrifuged at $3000 \mathrm{rpm}$ for 10 minutes at room temperature. The clear plasma was separated into a clean dry plastic container and used for the determination of P-selectin, Platelet activating factor, Platelet factor-4 and Gp Ilb/Illa complex. The remaining two and half millilitres $(2.5 \mathrm{ml})$ was dispensed into bottles containing di-potassium salt of Ethylenediamine tetra-acetic acid $\left(\mathrm{K}_{2}-\mathrm{EDTA}\right)$ at a concentration of $1.5 \mathrm{mg} / \mathrm{ml}$ of blood and used for platelet count.

\section{Methods of Sample Analysis}

\section{Ziehl-Neelsen technique for Mycobacterium tuberculosis diagnosis as described by WHO [11].}

\section{Procedure}

Smear preparation: A piece of clean stick was used to transfer and spread sputum materials evenly covering an area of about $15-20 \mathrm{~mm}$ diameter on a glass slide. The smear was air dried and labelled.

Heat fixation: The slide with the smear uppermost was rapidly passed three times through the flame of a Bunsen burner and allowed to cool.

Ziehl -Neelsen staining: The slide containing the smear was placed on a slide rack and the smear covered with Carbol Fuchsin stain. The stain was heated until vapour just begins to rise. The heated stain was allowed to remain on the slide for 5 minutes. The stain was washed off with clean water and then covered with $3 \% \mathrm{v} / \mathrm{v}$ acid alcohol for 5 minutes or until the smear is sufficiently decolorized, i.e. pale pink. The slide was washed off with clean water. The smear was covered with methylene blue stain for 1-2 minutes and then washed off with clean water. The back of the slide was wiped clean and placed in a draining rack for the smear to air-dry.

Microscopic examination of Ziehl-Neelsen stained smear: The smear was examined microscopically using the $100 x$ oil immersion objective.

Results: AFB - Red, straight or slightly curved rods, occurring singly or in small groups. Cells and background material appear blue. 


\section{Genexpert method for detection of Mycobacterium tuberculosis and rifampicin resistance (GeneXpert MTB/RIF).}

\section{Procedure}

The assay consists of a single-use multi-chambered plastic cartridge pre-loaded with the liquid buffers and lyophilized reagent beads necessary for sample processing, DNA extraction, and hemi-nested realtime PCR. Sputum samples were treated with the sample reagent (containing $\mathrm{NaOH}$ and isopropanol). The sample reagent was added in the ratio of 2:1 to the sputum sample and the closed specimen container was manually agitated twice during 15 minutes of incubation at room temperature. Two (2) $\mathrm{mls}$ of the treated sample was transferred into the test cartridge, the cartridge was loaded into the GeneXpert instrument and an automatic step will complete the remaining assay steps. The assay cartridge also contained lyophilized Bacillus globigii spores which served as an internal sample processing and PCR control. The spores was automatically re-suspended and processed during the sample processing step and the resulting B. globigii DNA was amplified during PCR step. The standard user interface indicates the presence or absence of $M$. tuberculosis, the presence or absence or Rifampicin resistance and a semi quantitative estimate of M. tuberculosis concentration (high, medium, low and very low). Assays that are negative for $M$. tuberculosis and also negative for $B$. globigii internal control was reported as invalid.

\section{Screening for HIV-1 and HIV-2}

Subjects were tested for HIV using Inverness Determine ${ }^{\mathrm{TM}} 1$ and 2 (Inverness Medicals Co. Ltd, Japan) and STAT-PAK (Chembio Diagnostic system, New York, USA). Uni-Gold (Trinity Biotech, Bray, Ireland) was used as the tie-breaker according to the national guidelines for HIV counselling and testing. Tests were carried out according manufacturer's instructions.

Platelet count as described by Lewis et al [6].

\section{Procedure}

A 1 in 20 dilution of well mixed blood was made in diluent by adding $20 \mu$ of blood to $0.38 \mathrm{ml}$ of ammonium oxalate $(10 \mathrm{~g} / \mathrm{l})$. Before the dilution, the blood sample was examined to rule out the presence of any blood clot. The suspension was mixed properly and an Improved Neubauer counting chamber was filled with the suspension using a Pasteur pipette. The counting chamber was placed in a moist Petri dish and left untouched for 20 minutes to give time for the platelets to settle. The preparation was examined using $x 40$ objective.

The platelet count was determined as follows;

Platelet count per litre $=\underline{\text { No of cells counted } \times \text { dilution } \times 10^{\underline{6}}}$

Volume counted $(\mu \mathrm{l})$ 


\section{Measurement of inflammatory cytokines and haemostatic parameters}

TNF-a, IL-10, IL-6, and IL-2 were assayed using enzyme-linked immunosorbent assays (ELISA) test kits from UCyTech Biosciences (Utrecht, Netherlands). The method employs quantitative sandwich enzyme immunoassay. A monoclonal antibody specific for human TNF-a, IL-10, IL-6, and IL-2 has been coated onto a microplate for each cytokine. Subsequently, $100 \mu \mathrm{L}$ of blank, diluted standard, controls, and samples were added to each well. The plates were sealed and incubated for 2 hours at $37^{\circ} \mathrm{C}$ and washed six times with the Wash buffer using the automated microplate Washer. Then, $100 \mu \mathrm{l}$ of the diluted detection antibody solution was added to each well and the plate was sealed and incubated for 1 hour at $37^{\circ} \mathrm{C}$. The washing step was repeated, and $100 \mu \mathrm{L}$ of diluted SPP conjugate was added to each well and the plates sealed and incubated for 1 hour at $37^{\circ} \mathrm{C}$. The washing step was repeated, and $100 \mu \mathrm{L}$ of TMB substrate solution was added into each well and incubated in the dark for $20 \mathrm{~min}$. The reaction was stopped with $100 \mu \mathrm{L}$ of stop solution. The results were evaluated using a Microplate reader at $450 \mathrm{~nm}$.

Additionally, TGF- $\beta$, P-SEL, GP Ilb/llla complex, TPO, PF-4, and PAF were assayed using ELISA kit from Elabscience Biotechnology Inc., (Wuhan, Hubei). The protocol for each parameter was carried out according to the manufacturer's instructions. A monoclonal antibody specific for human TGF- $\beta$, P-SEL, GP IIb/Illa complex, TPO, PF-4 and PAF has been coated on the wells. Subsequently, $100 \mu \mathrm{L}$ of blank, standard, controls, and samples were added to the micro ELISA plate well and incubated for $90 \mathrm{~min}$ at $37^{\circ} \mathrm{C}$. The liquid was removed without washing, and $100 \mu \mathrm{L}$ of Biotinylated Detection antibody working solution was immediately added to each well, covered with the Plate sealer, gently mixed, incubated for 1 hour at $37^{\circ} \mathrm{C}$, and washed three times using a Microplate washer. $100 \mu \mathrm{L}$ of horseradish peroxidase conjugate working solution was added to each well and incubated for $30 \mathrm{~min}$ at $37^{\circ} \mathrm{C}$. The washing step was repeated, and $90 \mu \mathrm{L}$ of substrate reagent was added and incubated for $15 \mathrm{~min}$ at $37^{\circ} \mathrm{C}$ in the dark. The reaction was stopped with $50 \mu$ of stop Solution. Results were evaluated using a microplate reader at $450 \mathrm{~nm}$.

\section{Statistical methods}

Statistical Package for Social Sciences software (IBM SPSS, Armonk, NY, USA) version 22 was used in data analysis. A normality test was conducted to assess the distribution of each variable using Kolmogorov-Smirnov statistic. Data were not normally distributed and thus were expressed as median (range), frequencies and percentages in tables, Bar chart and Pie chart.

Friedman ANOVA and post-hoc analysis with Wilcoxon Signed Rank test was applied for comparison of multiple repeated measurements (at Pre-treatment, 2-months and 6-months into therapy) and Spearman Rank Order correlation was used to test relationship between variables. $P<0.05$ was considered statistically significant.

\section{Results}


Majority of the participants were males (58.3\%), aged $18-30$ years (41.7\%) and married (60\%). The total mean age of the participants was $37.53 \pm 15.65$ years with an age-range of $18-65$ years. The mean age for males was $38.23 \pm 16.17$ years while that of females was $35.76 \pm 14.59$ years. Moreover about $63 \%$ of the participants had secondary education while only a few (6\%) had no educational qualification (Table 1).

Also most of the participants were traders (42\%), farmers (24\%) and students (21\%) (Figure 1).

The systolic and diastolic blood pressures were within the normal range at pre-treatment, 2-month and 6month into therapy (Figure 2).

The median levels of TNF- $\mathrm{a}(\mathrm{pg} / \mathrm{ml}), \mathrm{IL}-6(\mathrm{pg} / \mathrm{ml})$ and IL-2 $(\mathrm{pg} / \mathrm{ml})$ was significantly increased at 2-month compared to the pre-treatment value $(\mathrm{P}<0.001$ respectively). However, there was a significant decline at 6month into therapy compared to the value at 2-month into therapy $(P=0.025,0.006,<0.001)$. Furthermore, there was no significant change in the median levels of IL-10 (pg/ml) and TGF- $\beta(\mathrm{pg} / \mathrm{ml})$ at 2-month into therapy compared to the level at pre-treatment $(P>0.05)$. However, there was a significant increase at 6month into therapy compared to the level at pre-treatment and 2-month into therapy ( $P=0.020$ and 0.001$)$ (See table 2).

There was no significant change in the median values of PF-4 $(\mathrm{ng} / \mathrm{ml})$ at 2-month into therapy compared to pre-treatment $(P>0.05)$, but there was a significant decline at 6-month into therapy $(0.35)$ compared to 2-month into therapy and pre-treatment $(P=0.030)$. Moreover, there was a significant increase in the median levels of GP Ilb/llla $(\mathrm{ng} / \mathrm{ml})$ and PSEL $(\mathrm{ng} / \mathrm{ml})$ at 2-month into therapy compared with pretreatment $(P=0.037$ and 0.004$)$ and a significant decline at 6-month into therapy compared to the level at 2-month into therapy $(P=0.007$ and $<0.001)$. Furthermore, there was a significant increase in the median values of TPO $(\mathrm{pg} / \mathrm{ml})$ at 2-month into therapy compared to pre-treatment $(P=0.017)$. But no significant change at 6-month into therapy compared to 2-month into therapy $(P>0.05)$ (See table 3$)$.

Additionally, the Mean \pm SD of total platelet count $\left(\times 10^{9} / \mathrm{I}\right)$ increased significantly at 2-month into therapy $(281.92 \pm 93.22)$ compared to pre-treatment $(209.02 \pm 103.55)(P<0.001)$ and there was a further significant increase at 6-month (340.69 \pm 71.00$)$ compared to values at 2-month into therapy and pretreatment $(P<0.001)$.

There was a weak significant positive correlation between TNF- $\alpha$ and PF4 $(r=0.295 ; P=0.045)$ and a moderate significant positive correlation between TGF- $\beta$ and PF4 $(r=0.463 ; P=0.006)$. Also, there was a weak significant positive correlation between IL- 6 and P-selectin $(r=0.413 ; P=0.027)$ as well as between IL6 and TPO $(r=0.335 ; P=0.046)$. Conversely, there was a weak significant negative correlation between TGF- $\beta$ and PAF ( $r=-0.368 ; P=0.032)$ (See table 4$)$.

\section{Discussion}


Inflammation and haemostasis are two biological processes that considerably affect each other. Tuberculosis infection is marked by changes in inflammatory markers which could result in alterations in haemostatic parameters. This study assessed inflammation by measuring TNF-a, IL-6, IL-2 which are known pro-inflammatory cytokines as well as IL-10 and Transforming growth factor-beta (TGF$\beta)$ which are anti-inflammatory cytokines. Furthermore, the haemostatic variables assessed in this study were Platelet count, P-selectin, Platelet activating factor, Platelet factor-4, GP Ilb/Illa complex and Thrombopoietin hormone.

The finding showed that TNF-a, IL-6 and IL-2 levels significantly increased at 2-month into therapy and declined at 6-month into therapy. Since TNF- $a$ and IL-6 are known pro-inflammatory markers this finding gives a strong basis to conclude that 2-month into treatment is the peak of inflammation in TB subjects and that their pro-inflammatory activities are down-regulated at 6-months into therapy as seen in this study. According to Mootoo et al [12], TNF-a is an essential component of the innate defence mechanism of the host against pathogenic challenge and plays a major role in the pathology of Tuberculosis while IL6 it is a pleitropic pro-inflammatory cytokine with a wide range of biological activities in immune regulation, haematopoiesis, inflammation, oncogenesis and is of critical importance in acquired immunity against $M$. tuberculosis infection [13]. Thus the increase observed in TNF-a at 2-month into treatment, could be due to its inflammatory role which is coordinated via induction of other cytokines (such as IL-6) and the recruitment of immune and inflammatory cells. This may explain why a similar pattern of response was obtained for IL-6 in this study. Also, IL-2 has been shown to have multiple and sometimes opposing functions during an inflammatory response and in its dual and contrasting functions, it contributes to both the induction and termination of inflammatory immune responses [14]. Thus the significant increase at 2-month into treatment could be part of its contribution to the induction of inflammatory response. The haemostatic implication of the increased TNF-a level is an increase in platelet adhesion molecule expression as it has been shown to play a role in the up-regulation of adhesion molecules [15]. While the haemostatic implication of an increased IL-6 is a release of platelet because when IL- 6 reaches the bone marrow it promotes megakaryocyte maturation [16]. This agrees with the finding in this study of a persistent increase in platelet count up till 6-month into treatment. The decline of these cytokines at 6-month into treatment could be due to the reduction in inflammation as anti-inflammatory markers predominates. This correlates with our finding of elevated anti-inflammatory cytokines at 6-months which have been reported by Shalev et al. [17] to inhibit the inflammatory roles of TNF- $a$ and IL- 6 . It also confirms that the expression of these cytokines is strictly controlled, as their continual production can mediate damaging effects [18].

The IL-10 and TGF- $\beta$ level was significantly lower at pre-treatment and at 2-month into therapy, but increased significantly at 6-months into therapy. The significant reduction in IL-10 and TGF- $\beta$ at the early stage (pre-treatment and 2-month) compared to 6-month into therapy is of obvious benefits to the subjects. It has been found that an increased level or over-production of IL-10 in TB patients has been associated with immune-suppression and greater susceptibility to the disease [19] while an increased TGF- $\beta$ results in macrophage deactivation and suppression of T-cell responses to Mycobacterium tuberculosis. Similarly, the increase in the level of IL-10 and TGF- $\beta$ at the later stage of the infection (6- 
month into therapy) is also beneficial to the subjects as their role in modulation of inflammation and proinflammatory cytokines is necessary to avoid pathologic consequences that will result from an unregulated inflammatory process. This as earlier stated supports the reduction in IL-2, TNF-a and IL-6 observed in this study at 6 months into therapy.

In this study, a significant increase in platelet count was found at 2-month into therapy compared to pretreatment and a further significant increase at 6-month into therapy. According to lqbal et al. [20], platelet count has a significant role in immune functions and reactive thrombocytosis is generally seen in chronic inflammation. However, the findings of this study did not agree with that of Koju et al. [21] and lqbal et al. [20] that discovered a decreased platelet count from diagnosis till completion of initiation phase (at 2month) with resumption of normal platelet count during continuation phase of treatment. They attributed this observed decrease to Rifampicin which is considered as a major drug that decreases platelet count in anti-tuberculosis therapy. However, clinically low platelet counts are often associated with poor prognosis and increased risk for infection. In the light of this, the increased platelet count in our study is a sign of enhanced prognosis with treatment since the platelet count values were within the normal range.

This study also reported a significant increase in Thrombopoietin hormone (TPO) from the second month till 6-month into therapy where there was a slight but non-statistically significant decline. The reason for the significant increase at 2-month into treatment could mean that the hormonal increase is tied to the increase in inflammation and pro-inflammatory cytokines which peaks at 2-month into therapy. This thinking is re-enforced by the finding by Kaushansky [22] that in the liver, the production of TPO is augmented by IL- 6 . This is supported by the significant positive correlation between IL- 6 and TPO in our study. Thus it can be safely assumed that an increase in IL-6 at 2-month into treatment resulted to an increased TPO production. The increase could also have a direct relationship with the increased platelet count as it is known to regulate the production of platelets by stimulating the production and differentiation of megakaryocytes. The slight though non-significant decline at 6-month into therapy compared to 2-month into therapy may suggest that the process of reduction in TPO has set in with the down-regulation of pro-inflammatory cytokines observed at 6-month into treatment especially IL-6 which as earlier stated plays a role in the production of TPO. If this be the case then the rate of decline of TPO is not proportionate with rate of decline of inflammatory cytokines, thus the non-significant decline. It could also be due to the negative feedback resulting from a further significant increase in the platelet count at 6-month into therapy, this may have initiated the decline at 6-month into therapy though yet to be statistically significant.

This study found a significant increase in P-selectin (P-SEL) at 2-month into therapy and then a significant decrease at 6-month into therapy. P-selectin functions as a cell adhesion molecule and a marker of platelet activation and degranulation [23]. According Keane [15], TNF-a has been shown to play a role in the up-regulation of adhesion molecules of which P-selectin is one. Thus the significant increase in the level of P-selectin at 2-month into therapy which is the peak of inflammatory process in our study, points to the role of inflammation in up-regulation of the activity of P-selectin. This may also be linked to the weak significant positive correlation observed between IL-6 and P-selectin as well as the non-

Page $11 / 21$ 
significant positive correlation between TNF- $a$ and P-selectin. Functionally, P-selectin plays an essential role in the initial recruitment of leukocytes to the site of injury during inflammation and aggregation of platelet at areas of vascular injury [24]. The significant decline at 6-month into therapy shows that the activity of P-selectin wears off as the inflammatory cytokines recedes and anti-inflammatory markers dominates.

A significant increase in GP Ilb/Illa was seen at 2-months into therapy, followed by a significant decline at 6-months of therapy. The increase in GP Ilb/Illa complex at 2-month into therapy could also be a response to inflammation as TNF-a has been earlier stated to play a role in the up-regulation of adhesion molecules [15]. This argument is supported by our finding of a significant positive correlation between GP $\mathrm{Ilb} / \mathrm{Illa}$ and TNF-a. Also based on the significant negative correlation between GP Ilb/Illa and TGF- $\beta$ obtained in this study, the significant decline of GP Ilb/Illa at 6-month into therapy could be due to the down-regulation of inflammatory cytokines as earlier established in this study.

The findings of this study showed that Platelet factor-4 (PF-4) increased non-significantly at 2-month into therapy but decreased significantly at the 6-month into therapy. An elevated concentration of platelet factor- 4 could be used as an indicator for platelet activation since they are usually released from alpha granules of activated platelets. Elshamaa et al. [25] proved that PF-4 plays an important role in inflammation and wound repair and it is a strong chemo-attractant for neutrophils which is very crucial in the inflammatory process. Thus up-regulation and down-regulation of inflammation may be the reason for the non-significant increase at 2-month into therapy and decrease at 6-month into therapy. There was also a significant weak positive correlation between PF-4 and TNF-a.

Platelet activating factor (PAF) is important to the process of haemostasis because it causes platelets to aggregate and blood vessels to dilate [26]. In this study, there was a significant but weak negative correlation between TGF- $\beta$ (an anti-inflammatory marker) and PAF. High PAF level are associated with variety of conditions involving inflammation and it can trigger inflammatory and thrombotic cascades and mediate molecular and cellular interactions (cross-talks) between inflammation and thrombosis. This link between PAF and inflammation makes it unclear the reason for the non-significant decrease in PAF that was observed from the second month till the 6 month into therapy with increase and decrease in inflammation as well as the non-significant positive correlations with IL- 6 and TNF-a. However, since PAF is synthesized by two different pathways (de novo pathway and remodeling pathway) and the remodelling pathways (which is the primary source of PAF under pathological condition) is activated by inflammatory agents, the non-significant change could mean that the threshold or extent of inflammation was not sufficient to activate the remodeling pathway for PAF synthesis.

\section{Conclusion}

Pro-inflammatory response in TB subjects is highest at 2-month into therapy as indicated by an increase in TNF-a, IL-6 and IL-2 and is down-regulated at 6-month into therapy as indicated by a decrease in these cytokines, while anti-inflammatory response were highest at 6 month into therapy as indicated by an 
increase in IL-10 and TGF- $\beta$. The levels of P-selectin, GP Ilb/Illa, and TPO (haemostatic variables) are influenced by inflammation because they change accordingly with changes in pro-inflammatory cytokines in TB subjects. Thus it can be deduced that inflammation modulates the levels of these haemostatic variables in TB subjects.

\section{Abbreviations}

TB

Tuberculosis

TNF-a

Tumor Necrosis Factor Alpha

IL-6

Interleukin-6

IL-10

Interleukin-10

IL-2

Interleukin-2

TGF- $\beta$

Tissue Growth Factor beta

P-SEL

P-selectin

PAF

Platelet activating factor

TPO

Thrombopoietin

GP IIb/IIla

Glycoprotein IIb/Illa complex

ELISA

Enzyme linked immunosorbent assay

CDC

Centre for Disease Control

WHO

World Health Organization.

\section{Declarations}

\section{Acknowledgement}

Not applicable

\section{Funding}


Grant for this research was provided by Tertiary Education Trust Fund (TETFUND), Nigeria.

\section{Availability of data and materials}

The datasets used and/or analysed during the current study are available from the corresponding author on reasonable request.

\section{Authors' contributions}

COO conceived the study, collected data, carried out ELISA analysis, participated in statistical analysis and drafted the first manuscript. GIA Participated in the design of the study, data collection and manuscript revision and coordination of the study. POM participated in the study design, and manuscript revision. JOA contributed to the design of the study, data interpretation and critically revised the manuscript. $\mathrm{NCl}$ participated in data interpretation and manuscript revision. All authors read and approved the final manuscript.

\section{Ethics approval and consent to participate}

The study was approved by the Ethics committee of Federal Teaching Hospital Abakaliki (FETHA) (Ref: FETHA/REC/VOL.2/2018/105). The subjects gave informed consent before they were recruited into the study and confidentiality was ensured according to Helsinki declaration.

\section{Consent for publication}

Not applicable

\section{Competing interests}

The authors declare that they have no competing interests

\section{References}

1. World Health Organization. WHO Global TB Control Report 2012. Available at :http://www.who.int/ mediacentre/factsheets/fs104/en/ Accessed September 2018.

2. Centre for Disease Control. Tuberculosis report 2016. https://www.cdc.gov/globalaids/publications/mmwr_nigeriatb.html. Accessed January, 2019.

3. Ferrero-Miliani L, Nielsen OH, Andersen PS, Girardin SE, Nielsen AG. Chronic inflammation: importance of NOD2 and NALP3 in interleukin-1beta generation. Clin Exp Immunol.. 2007;147 (2): 06-11.

4. Tomioka H, Tatano Y, Sano C, Shimizu T. Development of new antituberculous drugs based on bacterial virulence factors interfering with host cytokine networks. J Infect Chem. 2011; 17 (3): 302317. 
5. Akpan PA, Akpotuzor JO, Akwiwu EC. Some Haematological parameters of tuberculosis (TB) infected Africans: The Nigerian perspective. J Nat Sci Res. 2012; 1: 14-18.

6. Lewis SM, Bain BJ, Bates I. Dacie and Lewis Practical Haematology $10^{\text {th }}$ edition Elsevier publishers, Philadelphia, India; 2006. p. 411.

7. Bonar R, Favaloro EJ, Adcock DM. Quality in coagulation and haemostasis testing. Bio Med. 2010; 20:184-199.

8. Verhamme P, Hoylaerts MF. Haemostasis and inflammation: two of a kind? Thrombosis Journal. 2009; 7: 15-17.

9. Margetic S. Inflammation and Haemostasis. Biochemia Medica. 2012; 22 (1): 49-62.

10. Akpan PA, Akpotuzor JO, Osim EE. The role of cytokines in fibrinolysis: A case study of active tuberculosis. J Infect Dis Med Microbiol. 2017; 1(1):1-5.

11. World Health Organization. Quality assurance of sputum microscopy in DOTS programmes 2003. www.wpro.who.int. Accessed 20 th August 2019.

12. Mootoo A, Stylianou E, Arias MA, Reljic R. TNF-alpha in tuberculosis: a cytokine with a split personality. Inflammation Allergy and Drug Targets. 2009; 8 (1): 53-62.

13. Martinez A.N., Mehra S., Kaushal D. Role of interleukin 6 in innate immunity to Mycobacterium tuberculosis infection. J Infect Dis. 2013; 207 (8): 1253-1261.

14. Hoyer KK , Dooms H, Barron L, Abbas AK. Interleukin-2 in the development and control of inflammatory disease. Immunol Rev. 2008; 226:19-28.

15. Keane J. TNF-blocking agents and tuberculosis: new drugs illuminate an old topic. Rheumatology. 2005; 44 (6): 714-720.

16. Tanaka T, Narazaki M, Kishimoto T. IL-6 in Inflammation, Immunity, and Disease. Cold Spring Harbor Perspectives in Biology. 2014; 6 (10): 1-25.

17. Shalev I, Schmelzle M, Robson SC, Levy G. Making sense of regulatory T cell suppressive function. Semin Immunol. 2011; 23: 282-292.

18. Cavalcanti YVN, Brelaz MCA., Neves JKA., Ferraz JC, Pereira VRA. Role of TNF-Alpha, IFN-Gamma, and IL-10 in the Development of Pulmonary Tuberculosis. Pulmonary Medicine. 2012; 2012: 1-10.

19. Guimarães TM, ToledoVP, Abreu MN. Evaluation of the Immune Response of individuals Infected with Mycobacterium tuberculosis and Patients with Active Tuberculosis. Immunology. 2012; 2012: $1-7$.

20. Iqbal S, Ahmed U, Khan MA. Haematological parameters altered in tuberculosis. Pak J Physio. 2015; $11(1): 13-16$.

21. Koju D, Rao B, Shrestha B, Shakya R, Makaju R. Occurrence of side effects from anti-tuberculosis drugs in urban Nepalese population under DOTS treatment. Kathmandu University Journal of Science, Engineering and Technology. 2005; 1 (1): 1-8.

22. Kaushansky K. Lineage-specific hematopoietic growth factors. N Engl J Med. 2006; 354 (19): 20342045. 
23. Kullaya $\mathrm{V}$, van der Ven A, Mpagama S, Mmbaga BT, Groot $P$ et al. Platelet-monocyte interaction in Mycobacterium tuberculosis infection. Tuberculosis. 2018; 111:86-93.

24. Cleator JH, Zhu WQ, Vaughan DE, Hamm HE. Differential regulation of endothelial exocytosis of Pselectin and von Willebrand factor by protease-activated receptors and cAMP. Blood. 2006; 107 (7): 2736-2744.

25. Elshamaa MF, Elghoroury EA, Helmy A. Intra-and postdialytic platelet activation, increased platelet phosphatidylserine exposure and ultrastructural changes in platelets in children with chronic uremia. J Med Sci. 2007; 7: 319-329.

26. Mclntyre TM, Prescott SM, Stafforini DM. The emerging roles of PAF acetylhydrolase. Journal of Lipid Research. 2009; 50: 255-259.

\section{Tables}

Table 1: Some Socio-demographic variables of the subjects.

\begin{tabular}{|c|c|c|c|}
\hline PARAMETER & & Frequency & Percentage (\%) \\
\hline \multirow[b]{2}{*}{ GENDER } & Male & 35 & 58.3 \\
\hline & Female & 25 & 41.7 \\
\hline \multirow{3}{*}{ AGE GROUP } & $18-30$ years & 25 & 41.7 \\
\hline & $31-50$ years & 21 & 35 \\
\hline & $>50$ years & 14 & 23.3 \\
\hline \multirow{3}{*}{ MARITAL STATUS } & Married & 36 & 60 \\
\hline & Single & 22 & 36.7 \\
\hline & Divorced & 2 & 3.3 \\
\hline \multirow{4}{*}{ EDUCATIONAL STATUS } & Primary & 17 & 21 \\
\hline & Secondary & 50 & 63 \\
\hline & Tertiary & 8 & 10 \\
\hline & None & 5 & 6 \\
\hline
\end{tabular}


Table 2: Median (range) levels of Pro and anti-inflammatory cytokines at pre-treatment, 2-months and 6months into therapy.

\begin{tabular}{|c|c|c|c|c|c|}
\hline DURATION & $\begin{array}{l}\text { TNF-a } \\
\text { (pg/ml) }\end{array}$ & IL-6 (pg/ml) & $\begin{array}{l}\mathrm{IL}-10 \\
(\mathrm{pg} / \mathrm{ml})\end{array}$ & $\begin{array}{l}\text { TGF-B } \\
(\mathrm{pg} / \mathrm{ml})\end{array}$ & $\mathrm{IL}-2(\mathrm{pg} / \mathrm{ml})$ \\
\hline \multirow{2}{*}{$\begin{array}{l}\text { (1) Pre-treatment } \\
(n=60)\end{array}$} & 1.55 & 66.12 & 1.46 & 23.83 & 11.36 \\
\hline & $\begin{array}{l}(1.55- \\
38.99)\end{array}$ & $\begin{array}{l}(4.08 \\
-267.65)\end{array}$ & $\begin{array}{l}(1.46 \\
-10.39)\end{array}$ & $\begin{array}{l}(23.83 \\
-148.83)\end{array}$ & $\begin{array}{l}(11.36 \\
-15.36)\end{array}$ \\
\hline \multirow[t]{2}{*}{ (2) 2-months $(n=60)$} & 86.54 & 172.90 & 2.77 & 23.83 & 16.98 \\
\hline & $\begin{array}{l}(1.23 \\
-934.95)\end{array}$ & $\begin{array}{l}(4.08 \\
-259.47)\end{array}$ & $\begin{array}{l}(1.46 \\
-9.20)\end{array}$ & $\begin{array}{l}(23.83 \\
-273.83)\end{array}$ & $\begin{array}{l}(11.36 \\
-467.48)\end{array}$ \\
\hline \multirow{2}{*}{$\begin{array}{l}\text { (3) 6-months } \\
(\mathrm{n}=60)\end{array}$} & 18.51 & 74.06 & 4.46 & 173.83 & 12.55 \\
\hline & $\begin{array}{l}(1.55 \\
-478.03)\end{array}$ & $\begin{array}{l}(4.08 \\
-247.53)\end{array}$ & $\begin{array}{l}(1.46 \\
-20.24)\end{array}$ & $\begin{array}{l}(23.83 \\
-5198.83)\end{array}$ & $\begin{array}{l}(11.36 \\
-36.81)\end{array}$ \\
\hline $\mathrm{X}^{2}$ value & 35.854 & 30.79 & 8.158 & 25.34 & 28.99 \\
\hline$P$-value & $0.000 *$ & $0.000 *$ & $0.017 \star$ & $0.000 *$ & $0.000 *$ \\
\hline 1 vs $2 P$-value & $0.000^{\star}$ & $0.000 *$ & 0.817 & 0.182 & $0.000 *$ \\
\hline 1 vs $3 P$-value & $0.000 *$ & $0.020 *$ & $0.002^{\star}$ & $0.000 *$ & $0.030 *$ \\
\hline 2 vs $3 P$-value & $0.025^{\star}$ & $0.006^{*}$ & $0.020 *$ & $0.001^{*}$ & $0.000^{*}$ \\
\hline
\end{tabular}

${ }^{\star} P<0.05$ is significant

TNF- $\mathrm{a}=$ Tumor Necrosis Factor alpha

IL-6 = Interleukin-6

$\mathrm{IL}-10=$ Interleukin-10

TGF- $\beta=$ Transforming growth factor beta

$\mathrm{IL}-2$ = Interleukin-2

1 vs 2 = Comparison of parameters at pre-treatment and 2-months into therapy.

1 vs $3=$ Comparison of parameters at pre-treatment and 6-months into therapy.

2 vs $3=$ Comparison of parameters at 2 -months and 6-months into therapy. 
Table 3: Median (range) levels of haemostatic variables at pre-treatment, 2-months and 6-months into therapy.

\begin{tabular}{|c|c|c|c|c|c|}
\hline DURATION & $\begin{array}{l}\text { PF-4 } \\
\text { (ng/ml) }\end{array}$ & $\begin{array}{l}\text { P-SEL } \\
\text { (ng/ml) }\end{array}$ & $\begin{array}{l}\text { GP Ilb/llla } \\
(\mathrm{ng} / \mathrm{ml})\end{array}$ & PAF (pg/ml) & TPO $(\mathrm{pg} / \mathrm{ml})$ \\
\hline \multirow{2}{*}{$\begin{array}{l}\text { (1) Pre-treatment } \\
(n=60)\end{array}$} & 0.37 & 22.12 & 4.87 & 3156.98 & 3603.03 \\
\hline & $\begin{array}{l}(0.35 \\
-3.32)\end{array}$ & $\begin{array}{c}(20.13 \\
-23.46)\end{array}$ & $(0.36-14.20)$ & $\begin{array}{l}(654.4 \\
-8963.97)\end{array}$ & $\begin{array}{l}(2898 \\
-5112.56)\end{array}$ \\
\hline \multirow[t]{2}{*}{ (2) 2-months $(n=60)$} & 0.38 & 23.22 & 6.63 & 2895.91 & 3966.04 \\
\hline & $\begin{array}{l}(0.35 \\
-6.29)\end{array}$ & $\begin{array}{l}(16.17 \\
-24.62)\end{array}$ & $(0.22-16.04)$ & $\begin{array}{l}(251.6 \\
-7557.91)\end{array}$ & $\begin{array}{l}(2957 \\
-4754.31)\end{array}$ \\
\hline \multirow[t]{2}{*}{ (3) 6-months $(n=60)$} & 0.35 & 21.94 & 3.47 & 2351.39 & 3899 \\
\hline & $\begin{array}{l}(0.35 \\
-2.41)\end{array}$ & $\begin{array}{l}(16.86 \\
-25.06)\end{array}$ & $(0.97-11.55)$ & $\begin{array}{l}(665.6 \\
-5499.17)\end{array}$ & $\begin{array}{l}(2661 \\
-5640.82)\end{array}$ \\
\hline$x^{2}$ value & 6.379 & 9.138 & 8.138 & 0.470 & 9.270 \\
\hline$P$-value & $0.044^{\star}$ & $0.015^{\star}$ & $0.035^{\star}$ & 0.791 & $0.010 *$ \\
\hline 1 vs $2: P$-value & 0.062 & $0.004^{\star}$ & $0.037^{*}$ & 0.581 & $0.017 *$ \\
\hline 1 vs 3: $P$-value & $0.041^{\star}$ & 0.114 & 0.094 & 0.098 & $0.020 *$ \\
\hline 2 vs 3: $P$-value & $0.030 *$ & $0.001 *$ & $0.007^{*}$ & 0.245 & 0.478 \\
\hline
\end{tabular}

$\star P<0.05=$ Significant

PF-4 = Platelet factor 4

P-SEL $=$ P-Selectin

GP IIb/IIla = Human platelet glycoprotein Ilb/IIla

$\mathrm{PAF}=$ Platelet Activating Factor

TPO $=$ Thrombopoietin hormone

1 vs 2 = Comparison of parameters at Pre-treatment and 2-months into therapy.

1 vs $3=$ Comparison of parameters at Pre-treatment and 6-months into therapy.

2 vs $3=$ Comparison of parameters at 2-months and 6-months into therapy. 


\begin{tabular}{|c|c|c|}
\hline Parameters & Correlation (rho) value & $P$-value \\
\hline TNF-a vs PF4 & 0.295 & $0.045^{\star}$ \\
\hline TNF- a vs P-SEL & 0.169 & 0.380 \\
\hline TNF- $a$ vs GP IIb/IIla & 0.372 & $0.031^{*}$ \\
\hline TNF- a vs PAF & 0.219 & 0.172 \\
\hline TNF- a vs TPO & 0.101 & 0.604 \\
\hline TNF- a vs PLT & 0.116 & 0.390 \\
\hline IL6 vs PF4 & 0.025 & 0.897 \\
\hline IL6 vs P-SEL & 0.413 & $0.027 *$ \\
\hline IL6 vs GP Ila/IIIa & 0.016 & 0.936 \\
\hline IL6 vs PAF & 0.092 & 0.635 \\
\hline IL6 vs TPO & 0.335 & $0.046^{*}$ \\
\hline IL6 vs PLT & 0.189 & 0.159 \\
\hline IL10 vs PF4 & -0.223 & 0.244 \\
\hline IL10 vs P-SEL & -0.256 & 0.181 \\
\hline IL10 vs GP Ila/IIIb & 0.033 & 0.864 \\
\hline IL10 vs PAF & 0.138 & 0.475 \\
\hline IL10 vs TPO & -0.168 & 0.384 \\
\hline IL10 vs PLT & 0.098 & 0.470 \\
\hline PF4 vs TGFB & 0.463 & $0.006^{*}$ \\
\hline TGF- $\beta$ vs P-SEL & 0.025 & 0.888 \\
\hline TGF- $\beta$ vs GP Ila/IIlb & -0.302 & 0.083 \\
\hline TGF- $\beta$ vs PAF & -0.368 & $0.032 *$ \\
\hline TGF- $\beta$ vs TPO & 0.043 & 0.809 \\
\hline TGF- $\beta$ vs PLT & -0.140 & 0.485 \\
\hline IL2 vs PF4 & -0.202 & 0.293 \\
\hline IL2 vs P-SEL & -0.086 & 0.659 \\
\hline IL2 vs GP Ila/IIlb & 0.089 & 0.645 \\
\hline IL2 vs PAF & 0.216 & 0.261 \\
\hline
\end{tabular}




\begin{tabular}{|lll|}
\hline IL2 vs TPO & 0.073 & 0.706 \\
\hline IL2 vs PLT & 0.074 & 0.586 \\
\hline
\end{tabular}

${ }^{*} P<0.05=$ Significant.

vs $=$ versus

\section{Figures}

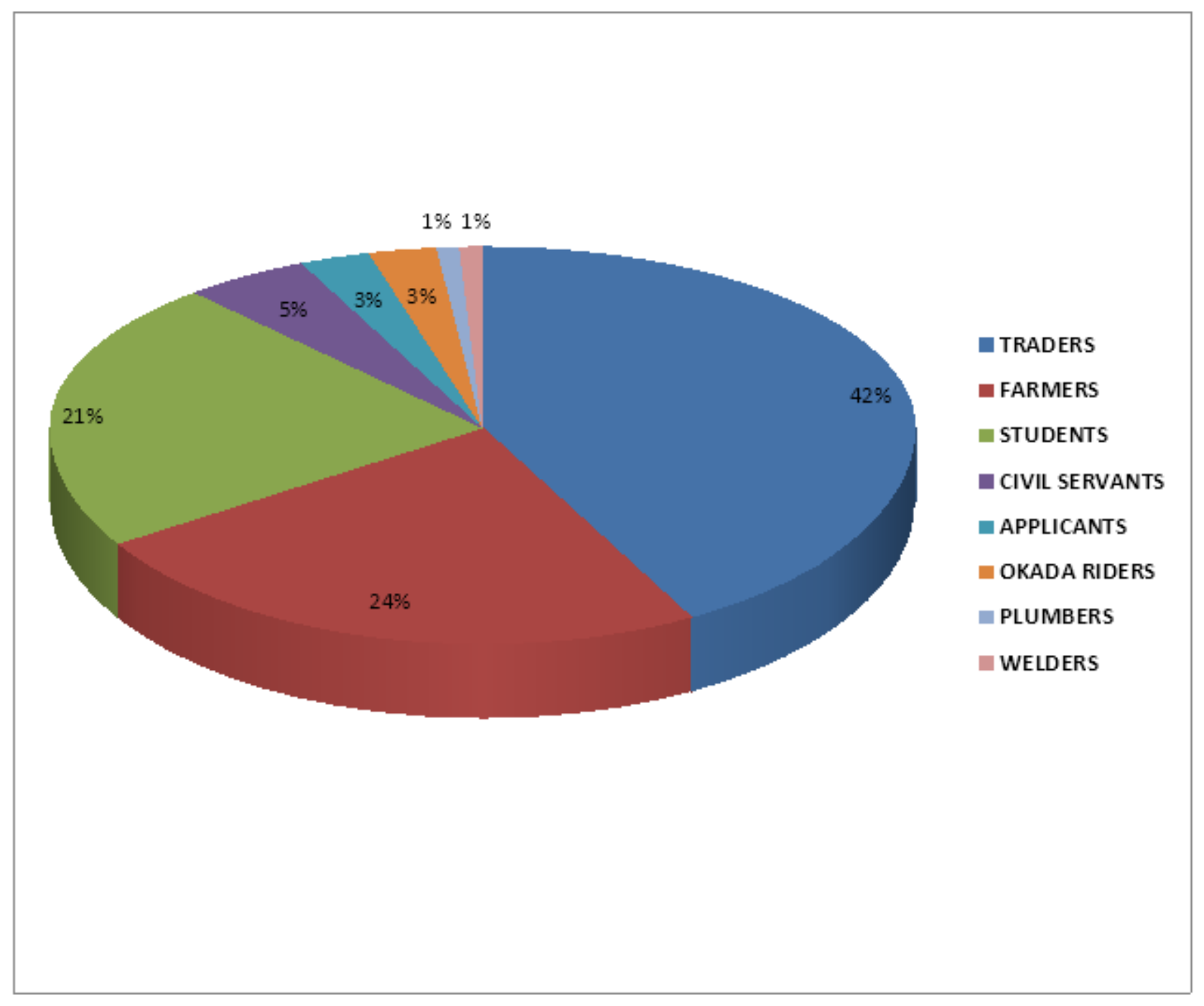

Figure 1

A pie chart showing the occupational distribution of the subjects. 


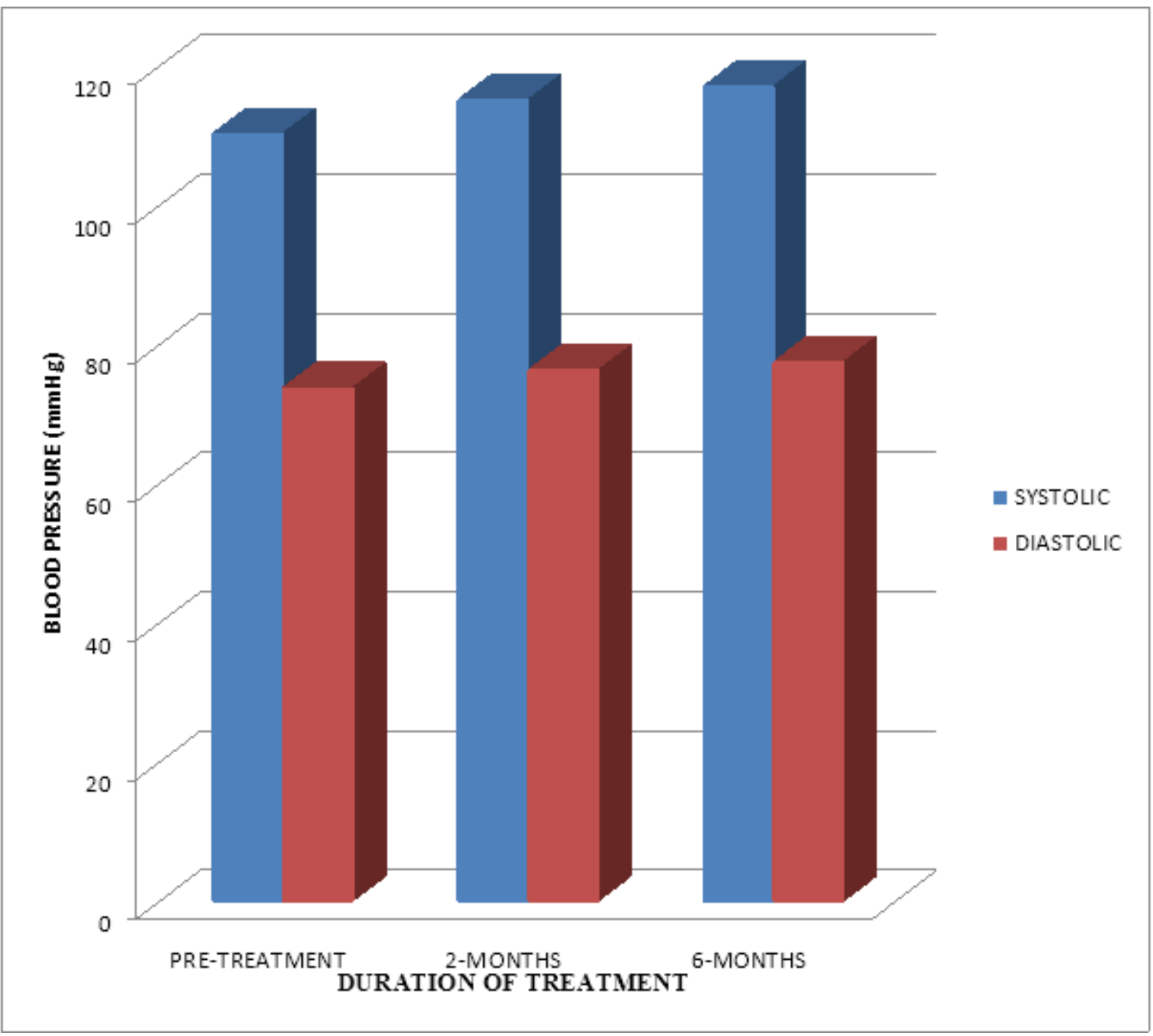

Figure 2

A bar chart showing the blood pressure values $(\mathrm{mm} / \mathrm{Hg})$ at pre-treatment, 2-month and 6-month into therapy. 